\title{
Genetic Resources of Temperate and Subtropical Fruit and Nut Species at the Nikita Botanical Gardens
}

\author{
Valery N. Yezhov, Anatoly V. Smykov, Vladimir K. Smykov, and Sergei Yu. Khokhlov \\ Nikita Botanical Gardens, National Scientific Center, Yalta, Crimea, Ukraine, 98648 \\ David E. Zaurov, Shawn A. Mehlenbacher, ${ }^{1}$ Thomas J. Molnar, \\ Joseph C. Goffreda, and C. Reed Funk \\ Department of Plant Biology \& Pathology, Foran Hall, 59 Dudley Road, Cook College, Rutgers University, New \\ Brunswick, NJ 08901-8520
}

Additional index words. germplasm, breeding, peach, pear, plum, apricot, nuts

The Nikita Botanical Gardens (NBG), established in 1812, is the oldest botanical garden in the former Soviet Union. The NBG belongs to the Ukraine Academy of Agrarian Sciences and acts as a comprehensive scientific research institute, botanical garden, and tourist attraction. The core botanical garden is located near Yalta, on the Black Sea coast of the Crimean peninsula (Fig. 1). The NBG also has branch research stations within the Crimean peninsula and in the steppes of the Kherson oblast (oblast is synonymous with province).

The name Nikita comes from the small village settled by Greeks several centuries previously, near which the original plots of land were allotted for the Gardens. The Novorossiysk general governor A. Plessy du Richelieu, greatgrandson of Cardinal du Richelieu, proposed establishing the botanical gardens. In 1811, a decree was signed in St. Petersburg and the first plantings were made in September 1812, marking the birth of the NBG. Christian Steven, a prominent young scientist of the time, was invited to fill the position of director at the new Gardens. Since there was a need for guidance in the development of southern horticulture and the need for appropriate planting stock, Steven decided the central aim of the Gardens would be the introduction and development of new plants suitable for growing in southern Russia. Within 12 years, Steven had contacted 40 institutions and private growers, who sent plant material from various parts of Europe. He collected a total of 450 ornamental species along with a large number of temperate and subtropical fruit species. Mr. Steven also founded a herbarium and library.

The scientific activities of the NBGincludes studying plant resources of the world, with an emphasis on the introduction, selection, and genetic improvement of disease and pest resistant, high yielding, high quality cultivars of temperate and subtropical fruit, nuts, spices, ornamental, and essential oil-bearing plants. Research is also being conducted on the physiology, biology, and culture of many of these species as well as management of their pests and diseases. Presently, the collection of temperate

Received for publication 17 Feb. 2004. Accepted for publication 31 May 2004.

${ }^{1}$ Department of Horticulture, 4017 Agricultural and Life Sciences Bldg., Oregon State University, Corvallis, OR 97331-7304 . sellowiana Berg.). Rev. 2, February 2003). and subtropical fruit and nut species holds 7,685 accessions made up of cultivars, selections, and unique forms (Table 1). The collections include peach and nectarine [Prunus persica (L.) Batsch.], apricot (Prunus armeniaca L.), European plum (Prunus domestica L.), cherry-plum (Prunus cerasifera Ehrh.), sour cherry (Prunus cerasus Ehrh.), apple (Malus xdomestica Borkh.), pear (Pyrus communis L.), quince (Cydonia oblonga Mill.), almond [Prunus dulcis (Mill.) D. A. Webb.], walnut (Juglans regia L.), hazelnut (Corylus avellana L.), pomegranate (Punica granatum L.), fig (Ficus carica L.), persimmon(Diospyros spp.), Chinese date (Zyzyphus jujuba Mill.), hardy kiwifruit (Actinidia spp.), pawpaw [Asimina triloba (L.) Dunal], lemon [Citrus limon (L.) Burm.], and feijoa or pineapple guava (Feijoa

There are nine departments in the Gardens: flora and vegetation, dendrology and floriculture, subtropical fruit culture, essential oil-bearing and medicinal plants, agroecology

Fig. 1. Map of Ukraine (reproduced with permission from the Dept. of Public Information, Cartographic Section, United Nations, Map 3773,

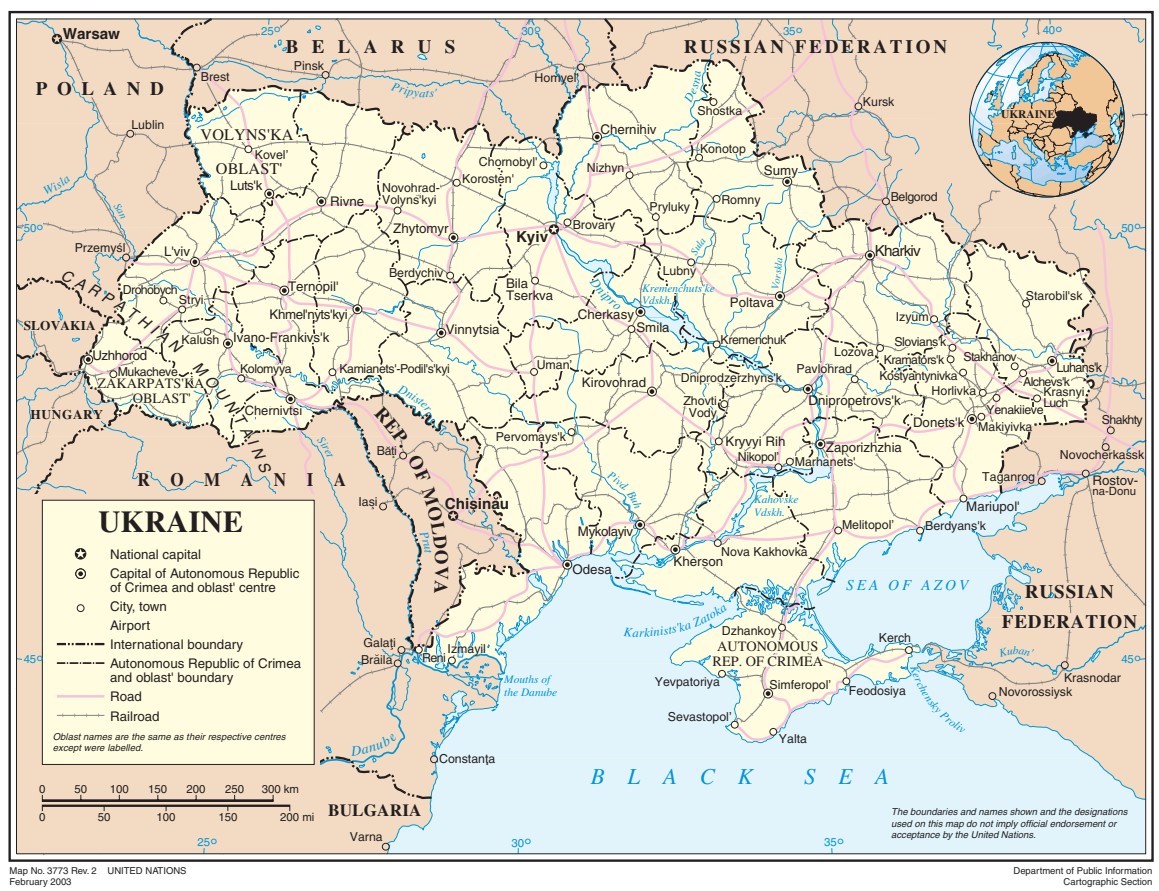

and plant protection, reproductive biology and physiology of plants, biotechnology and biochemistry, plant management, and market-

Table 1. Number of accessions of temperate and subtropical fruit and nut species held in collections at the Nikita Botanical Gardens.

\begin{tabular}{lr}
\hline Species & Total \\
\hline Almond & 1,103 \\
Apple & 760 \\
Apricot & 783 \\
Cherry & 541 \\
Cherry plum & 220 \\
Chinese date & 140 \\
Feijoa (pineapple guava) & 400 \\
Fig & 334 \\
Hardy kiwifruit (Actinidia sp.) & 11 \\
Hazelnut & 55 \\
Lemon & 10 \\
Olive & 230 \\
Pawpaw & 16 \\
Peach and nectarine & 1,284 \\
Pear & 351 \\
Persimmon & 190 \\
Plum & 493 \\
Pomegranate & 370 \\
Quince & 219 \\
Walnut & 175 \\
\hline
\end{tabular}

Quince 
ing. The research staff today consists of 187 workers, including $75 \mathrm{PhD}$ scientists, 2 postdoctoral scientists, and 47 graduate students. The gardens have 5 industrial and experimental branches: Central (in Yalta), Primorskoe (16 $\mathrm{km}$ east of Yalta), Stepnoe (12 km north of Simferopol), Novokakhovskoe (2 km south of Novaya Kakhovka, Kherson oblast), and the Dzhankoy introduction quarantine facility (6 km north of Dzhankoy) (Fig. 1). The total area occupied by the NBG, including all of its branch stations, is 1,835 ha.

Accessions are evaluated for adaptation to a range of climatic conditions, since the collections and research stations are located in two very different climatic zones. This includes the south coast of Crimea where subtropical plants grow and the steppe region where air temperature can drop to $-30{ }^{\circ} \mathrm{C}$. Mountain ranges stretch across southern Crimea creating a narrow band (about $2 \mathrm{~km}$ wide by 200 $\mathrm{km}$ long) of Mediterranean climate along the south coast (although microclimates vary considerably depending on elevation, exposure, and degree of slope). A transition to a more continental climate quickly occurs as you move north and away from the coastline.

\section{Breeding Activities at the NGB}

Peach and nectarine. The first peach breeder at the NBG was Ivan N. Ryabov (1923-1984). He devoted over half his life to peach culture, breeding, and classification. Ryabov made many trips to Central Asia and the Trans-Caucasus to collect and study the diverse peach germplasm found there. His collections became the base of the NBG peach genetic improvement program, yielding dozens of new cultivars used in commercial orchards of the southern regions of the former Soviet Union (Andriyenko, 1997).

In 1978, Vladimir K. Smykov became director of the NBG fruit breeding program. Previously he worked for $>20$ years at the Moldavian Institute of Horticulture, Viticulture, and Wine Production. During his work in Moldova, Smykov established large collections of apple, peach, apricot, and pear germplasm that resulted in the release of $>50$ new cultivars. Much of this material was brought to the NBG with his arrival. Smykov subsequently utilized many horticultural techniques including radiation mutation breeding, interspecific hybridization, and isozyme analysis (Smykov and Lischuk, 1999).

Vladimir K. Smykov, Anatoly V. Smykov, and Tatyana A. Latsko currently carry out the breeding and study of peach at the NBG. The main peach research is at the Central branch of the NBG, with additional testing and improvement at the Stepnoe branch. Over a period of 20 years, 30 new cultivars were developed at the $\mathrm{NBG}, 3$ of which are planted commercially in the steppe region of Ukraine. Additional selections are currently undergoing evaluation in state and industrial cultivar trials. Early ripening, yellowfleshed cultivars of peach were obtained and used in the breeding program (Table 2), as were small-sized tree forms. In addition, Smykov has worked out a complex method of selection for peach (Smykov and Lischuk, 1999).
Peach cultivars developed at the NBG typically flower during the last week of April and ripen over an extended period between the first weeks of July to the third week of September. The earliest maturing cultivar in the collection is 'Favorita Morettini'. 'Granatovy' and 'Yubileyny Ranny' ripen 2 to $3 \mathrm{~d}$ later, have larger, more attractive fruit with a higher percent overcolor, and are very flavorful (Table 2). 'Pontiysky' and 'Demerdzhinsky' ripen one week later than 'Favorita Morettini', and have large, brightly colored fruit. 'Demerdzhinsky' also has cold hardy flower buds and is more frost resistant than many of the other cultivars. 'Krymsky Feyerverk' has shown good commercial performance, with a very high fruiting potential, and a tree form that rarely needs pruning. It endures the Crimean winters very well, and has attractive, very flavorful fruit. 'Sagdiets' has shown a high level of resistance to frost and powdery mildew [Podosphaera leucotricha (Ell. et Ev.) Salmon], while also having very large and flavorful fruit. 'Startovy' has shown outstanding commercial performance with consistent fruit set in the contrasting temperature conditions of the different climatic zones of Crimea. It has large flavorful fruit with firm flesh. 'Dostoyny' is of great interest due to its attractive fruit that has shown good transportability. It is also the only cultivar from the NBG used for canning. The remaining cultivars (Table 2) are mainly eaten fresh, made into jam, or dried. 'Otlichnik' is characterized by the development of plentiful flower buds. 'Posol Mira' has shown outstandingly high yields, high resistance to cold and

Table 2. Characteristics of peach cultivars released by the Nikita Botanical Gardens from 1994 to 2004.

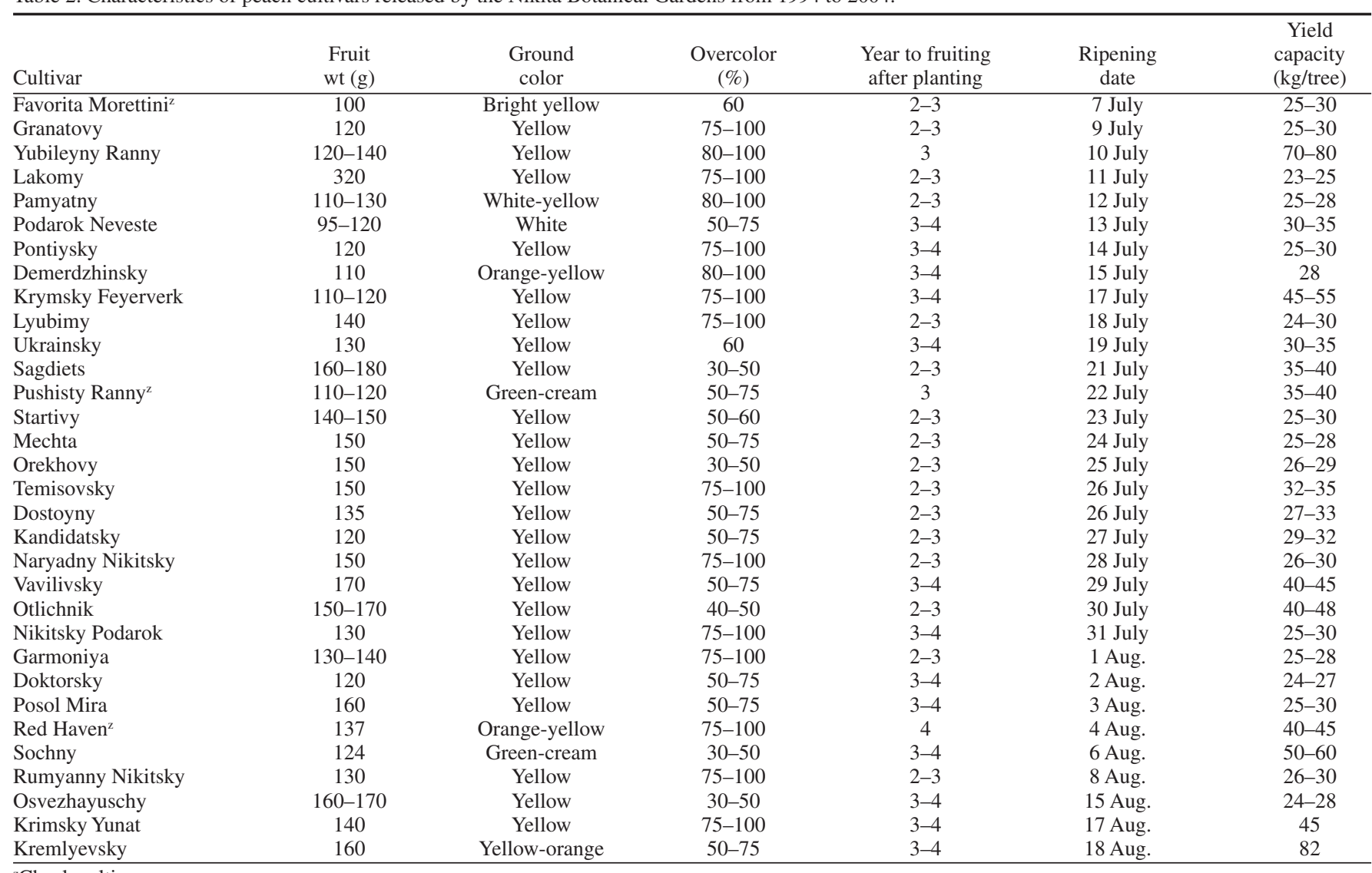

${ }^{2}$ Check cultivar. 
spring frosts, plentiful flower buds, and large $(>150 \mathrm{~g})$ attractive fruit with firm flesh. The peach cultivars that ripen in September are 'Muza' and 'Krymskaya Osen' with yellow flesh and 'Turist' with white flesh. Many years of commercial evaluation have shown these cultivars to be broadly adapted to diverse climatic conditions, along with having superior market quality.

The NBG has the largest nectarine collection in Ukraine, containing 261 accessions. The main breeding objectives include developing nectarines with large size fruit, resistance to disease, drought tolerance, cold hardiness, excellent taste, and superior market quality. Evgeniy F. Shoferistov currently heads the nectarine improvement program. Almond has also been used in the hybridization program, resulting in a unique germplasm collection of almond and distant hybrids. The original nectarine cultivars for commercial orchards were developed at the NBG. 'Rubinovy 8' is included in the Ukraine State List of Selection Achievements, and 11 promising NBG cultivars are now in state cultivar tests.

\section{Top NBG nectarine cultivars}

'Ametist'. Result of a controlled cross between 'Nectaheart' and 'Le Grand'. The tree is medium size with rose type (showy) flowers, fertile pollen, and 130 to $160 \mathrm{~g}$ freestone fruit. The yield capacity of a 7-year-old tree is 29 $\mathrm{kg} /$ tree. The fruit ripens from 1 to $20 \mathrm{Aug}$. The skin is yellow with a $75 \%$ to $100 \%$ over color of dark carmine.

'Evpatoriysky'. Originated from a seedling of an unknown Central Asian nectarine. The tree is medium size with rose type (showy) flowers, fertile pollen, and 75 to $115 \mathrm{~g}$ freestone fruit. The yield capacity of an 8- to 10-year-old tree is 35 to $45 \mathrm{~kg} /$ tree. The fruit ripens between the 10 and 20 Aug. The skin is yellow with a $75 \%$ to $100 \%$ over color of dark pink to bright carmine.

'Ishunsky'. Originated from a seedling of an unknown Central Asian nectarine. The tree is medium size with rose type (showy) flowers, fertile pollen, and 92 to $148 \mathrm{~g}$ freestone fruit.
The yield capacity of an 8- to 10-year-old tree is $38 \mathrm{~kg} / \mathrm{tree}$. The fruit ripens from the $20 \mathrm{Aug}$. to the end of August. The skin is yellow with a $25 \%$ to $50 \%$ over color of bright carmine.

'Rubinovy 8'. Selected from seed progeny of 'Kentavr' peach. The tree is medium size with fertile pollen and 151 to $179 \mathrm{~g}$ freestone fruit. The yield capacity of an 8- to 10-year-old tree is 50 to $60 \mathrm{~kg} /$ tree. The fruit ripens from 20 Aug. to 10 Sept. The skin is yellow with a $75 \%$ to $100 \%$ over color of dark carmine.

Ornamental Prunus. Ivan N. Ryabov, Irina V. Kryukova, and Valentina P. Orekhova have introduced and selected ornamental fruit cultivars, creating the largest collection in the former Soviet Union. The collection holds 50 cultivars (developed by the NBG and introduced from France, Iran, Korea, and China) and 20 selections expressing desirable breeding characteristics, belonging to four different Prunus species. Ornamental peach cultivars differ in flower color, flower form, petal number, crown shape and structure, bloom period, frost resistance, and disease resistance. Larissa D. Komar-Tyemnaya is currently continuing the ornamental Prunus program at the NBG.

The new and noteworthy cultivars 'Solveyg' and 'Zhizel' exhibit vigorous growth, thin crowns, and light purple and purple-pink double flowers respectively, that are $50 \mathrm{~mm}$ in diameter. They are also resistant to powdery mildew [Podosphaera leucotricha (Ell. et Ev.) Salmon] and peach leaf curl (Taphria deformans Jacz.) and have been a success in state cultivar testing. 'Ruteniya', 'Lel', and 'Fler Pompon' are very promising and are currently being tested. 'Ruteniya' has purple-pink bell-form flowers. 'Lel' is unique for its small half-double flowers that are lilac-pink. 'Fler Pompon' has light purple-pink flowers with 60 to 100 petals. All cultivars mentioned blossom over a 20 -d period with a great abundance of flowers and pleasant aromas.

Apricot. Klavdiya F. Kostina was the first to begin work with apricot (Prunus armeniaca) at the NBG. She made many expeditions to Central Asia, the Trans-Caucasus, and Ukraine to collect the rich and valuable apricot germplasm naturally occurring there. In addition to collecting vast amounts of germplasm, she also developed a botanical-geographical classification of the very genetically diverse species. Based on her studies, apricot cultivars were placed into four groups: Central Asian, Dzhungarsko-Zailiysky, Irano-Caucasian, and European (Kostina, 1936).

Intensive breeding work was done using the large germplasm holdings collected by Kostina. An emphasis was placed on making controlled crosses between unrelated cultivars and selections from geographically distant areas. All of the cultivars used on the industrial plantations in the southern part of the former Soviet Union resulted from this breeding method (Andriyenko, 1997; Smykov and Lischuk, 1999).

Vladimir K. Smykov has led the research and breeding of apricot at the NBG since 1978, developing new cultivars with improved cold hardiness, such as 'Crimsky Medunets'. This allowed the expansion of apricot culture into new regions (Smykov, 1989). Cultivars bred at the NBG were tested and finally commercialized in Ukraine, Moldova, Bulgaria, and Romania. At present, Smykov and Gorina continue the breeding program.

Cherry-plum. In addition to her work with apricot, Kostina did much distinguished work with the large-fruited cherry plum (Prunus cerasifera). She used the local Crimean forms and made distant hybridizations with cultivars of Chinese plums (Prunus spp.), developing cultivars that quickly spread in use over the southern regions of the former Soviet Union. Culture of cherry-plum is attractive because trees are precocious, have high yield potential, and the fruit matures early and has multiple uses. Today, Gorina continues the program of evaluation and breeding of cherry-plum.

\section{Top NBG cherry-plum cultivars}

'Obilnaya'. Middle-late ripening cultivar with large dark-purple to dark-violet 35 to $60 \mathrm{~g}$ fruit. The flesh is yellow, firm, sour-sweet, and aromatic. This cultivar has good transportability

Table 3. Characteristics of apple cultivars released by the Nikita Botanical Gardens from 1994 to 2004.

\begin{tabular}{|c|c|c|c|c|c|c|c|}
\hline Cultivar & $\begin{array}{l}\text { Fruit } \\
\text { wt (g) }\end{array}$ & Color & $\begin{array}{l}\text { Ripening } \\
\text { date }\end{array}$ & $\begin{array}{l}\text { Shelf life } \\
\text { (until) }\end{array}$ & $\begin{array}{c}\text { Yield } \\
\text { (kg/tree) }\end{array}$ & $\begin{array}{l}\text { Growth } \\
\text { habit }\end{array}$ & $\begin{array}{l}\text { End } \\
\text { use }\end{array}$ \\
\hline Plat & 120 & Yellow with red blush & 20-30 July & August & 16 & Medium size & Fresh, juice \\
\hline Colorist & 150 & Green-yellow & 20-30 July & August & 17 & Medium size & Fresh \\
\hline August & 130 & Yellow with red blush & 1-10 Aug. & November & 16 & Compact & Fresh, juice \\
\hline Naslednitsa Yuga & 140 & Orange-red & 10-20 Aug. & September & 15 & Small & Fresh, juice \\
\hline Vashernyaya Zarya & 170 & Orange & 1-10 Sept. & November & 20 & Medium size & Fresh, juice \\
\hline Malinovy Delicious & 200 & Yellow with red blush & 1-10 Sept. & November & 18 & Medium size & Fresh, juice \\
\hline Utrennyaya Zorka & 180 & Bright crimson & 1-10 Sept. & November & 17 & Medium size & Fresh, juice \\
\hline Kodrovskoe & 150 & Red blush & 10-20 Sept. & October & 17 & Small & Fresh \\
\hline Luchafer & 130 & Yellow with red blush & 10-20 Sept. & October & 16 & Small & Fresh \\
\hline Kalvil Moldavsky & 150 & Orange & 20-30 Sept. & April & 21 & Medium size & Fresh \\
\hline Norok & 200 & Bright crimson & 20-30 Sept. & March & 24 & Small & Fresh, juice \\
\hline Pepin Moldavsky & 190 & Green-red & 20-30 Sept. & February & 16 & Small & Fresh \\
\hline Ranet Moldavsky & 150 & Yellow with blush & 20-30 Sept. & February & 17 & Small & Fresh \\
\hline Aurel & 160 & Yellow with red blush & 20-30 Sept. & March & 16 & Medium size & Canning \\
\hline Buzhor & 150 & Dark crimson & 20-30 Sept. & April & 17 & Small & Fresh \\
\hline Moldavskoe & 140 & Yellow with red blush & 20-30 Sept. & February & 20 & Medium size & Fresh, juice \\
\hline Krasnoye & 160 & Dark red & 20-30 Sept. & March & 19 & Medium size & Fresh \\
\hline Sperantsa Yarna & 190 & Yellow with red blush & 20-30 Sept. & March & 18 & Medium size & Fresh \\
\hline Vagnera Novoye & 130 & Yellow with red blush & 20-30 Oct. & May & 25 & Small & Fresh \\
\hline Rumyanny Alpinist & 150 & Bright green & 20-30 Oct. & June & 26 & Medium size & Fresh \\
\hline
\end{tabular}


and consistent and plentiful fruiting.

'Olenka'. Late-ripening cultivar with dark-red 25 to $33 \mathrm{~g}$ fruit. The flesh is yellow-cream colored, firm, and aromatic. This cultivar has good transportability, high yield capacity and consistent fruiting.

'Krymskaya Sharovidnaya'. Middle-late ripening cultivar with dark orange-red 25 to $50 \mathrm{~g}$ fruit. The flesh is cream colored and juicy, with a balanced sour-sweet taste. This cultivar has good transportability, drought resistance, high yield capacity, and consistent fruiting.

'Rumyannaya Zorka'. Late-ripening cultivar with orange-yellow raspberry blush 28 to 60 $\mathrm{g}$ fruit. The flesh is bright yellow, firm, and juicy with a sour-sweet taste. This cultivar has good transportability, high yield capacity, and consistent fruiting.

Plum. Klavdiya F. Kostina also paid great attention to plum, Prunus domestica. She developed many valuable cultivars. One named 'Vengerka Krupnaya' is still used today for commercial plantations in Ukraine and Moldova. A large number of plum cultivars and selections from Moldova and Yugoslavia were received from Moldova in 1978 with the arrival of Vladimir K. Smykov. Many of them (for example 'Vengerka Yubileinaya') have performed well under Crimean conditions.

Sour cherry. Ivan N. Ryabov developed the large sour cherry (Prunus cerasus) improvement program at the NBG. He bred many valuable cultivars and some of them ('Zarya Vostoka' and 'Yantarnaya') are still used today for commercial plantations in Ukraine. At present, Lyubov A. Lukichova works with cherry culture at the NBG. Recently, early-ripening cultivars with large fruit and high market quality were selected from previous cherry hybrid populations held at the Gardens. The newly selected cultivars 'Znatnaya' and 'Kutuzovka' are quite remarkable due to their resistance to cracking during wet weather. Hungarian sour cherry cultivars, such as 'Erdi Botermo', are the most promising in the sour cherry collection.

Apple. Widespread introduction and breeding of apple at the Gardens began in 1978 with the arrival of Vladimir K. Smykov. He introduced and developed an assortment of apple cultivars from very early-ripening selections to selections with great fruit storage quality (Table 3). For example, 'Vagnera Novoye' and 'Rumyanny Alpinist' successfully went through state cultivar testing where they showed great storage quality, precocity, early maturity, high resistance to cold and diseases, and excellent marketability with high quality, great tasting fruit. A number of cultivars are drought resistant and have extended periods of bloom. All apple cultivars listed in Table 3 fruit within 2 to 3 years when grafted on 'M.9' rootstock. Today, Vladimir K. Smykov and Nadezhda A. Litchenko continue work on introduction, evaluation, and breeding of apple.

Pear. Research on pear (Pyrus communis L. and P. serotina Rehd.) is done by Valentina L. Baskakova and Sergei Yu. Khokhlov. The most promising $P$. communis in the collection are from Moldova, and the best $P$. serotina are from Japan and China. Moldavian cultivars perform well under Crimean conditions with excellent fruit storage quality under refrigeration. Cultivars of $P$. serotina have become popular due to their crunchy, juicy flesh and unique, pleasant aroma.

Quince. Today, Valentina L. Baskakova continues the quince program initiated by Klavdiya D. Dorogobuzhina in 1940. The quince germplasm collection contains $>200$ cultivars and forms. Six industrially important cultivars have been developed at the NBG. Quince fruit is high in pectin and is good for jams, syrup, and candied fruits. Unique precocious and early maturing types with stable yield capacity and minimal pesticide needs were developed at the Gardens and allow for ecologically clean, high quality fruit production useful for processing and confectionary.

Almond. AlexanderA. Rikhter began breeding almonds at the NBG in 1930. At that time, many cultivars and forms of almond were collected from Central Asia, the Trans-Caucasus, Western Europe, and North America (Rikhter, 1972). Currently, the collection includes 6 species and $>1,000$ cultivars, selections, and unique forms developed at the NBG and collected from Uzbekistan, Tajikistan, Armenia, U.S., Italy, France, Spain, Hungary, Bulgaria, Greece, and Iran. The main breeding objectives are to develop improved late-flowering cultivars with a stable period of flower bud dormancy, high productivity, and $>40 \%$ kernel with a small percentage of double kernels.

In Crimea and southern regions of Ukraine, cultivars developed at the NBG perform very well. These include 'Primorsky' (half-dwarf cultivar), 'Vynoslivy', 'Desertny', 'Nikitsky 2240', and 'Nikitsky Pozdnotsvetuschy' (Rikhter, 1975). Among the older cultivars, 'Stepnoy' (late blooming, early ripening) and 'Foros' are the best. Currently, Irina G. Chernobay continues the almond evaluation and breeding work at the gardens.

Walnut. In 1964 an extensive persian walnut (Juglans regia) germplasm collection was developed as a result of many expeditions to Central Asia, the Trans-Caucasus, and Ukraine. At present, the collection contains 175 cultivars and $>50$ selections expressing desirable breeding characteristics (Rikhter and Yadrov, 1985). The main breeding objective is to develop cultivars with high yield capacity, large nuts with $>45 \%$ kernel, small tree size, resistance to Marssonina juglandis (Lib.) Magnus and Xanthomonas campestris pv. juglandis (Pierce) Dye, and late simultaneous blooming of male and female flowers. All forms, cultivars, and hybrids growing in the collection and experimental plantations, were studied in detail according to the methods worked out by Rikhter(1981). Eleven forms that have compact crowns and small tree size were obtained using radiation mutation breeding. These traits are heritable and the forms have relatively high yield capacity and large, good tasting nuts of market quality. Today, Sergei Yu. Khokhlov and N.G. Popok continue evaluation and breeding work on walnut at the NBG.

\section{Selected walnut cultivars of the NBG}

'Belbeksky 70'. The trees are large size $(8 \mathrm{~m})$, late leafing and blooming, and annual fruiting with a yield capacity of $20 \mathrm{~kg} /$ tree with an average nut weight of $10.7 \mathrm{~g}$. The shell is light yellow, of moderate thickness $(1.8 \mathrm{~mm})$, and firm. Percent kernel is $51.3 \%$ with a fat content of $61.5 \%$.

'Vynoslivy'. The trees are medium size $(6 \mathrm{~m})$ and annual fruiting with a yield capacity of 40 $\mathrm{kg} / \mathrm{tree}$ and an average nut weight of $10.8 \mathrm{~g}$. The shell is light yellow, of moderate thickness (1.9 $\mathrm{mm}$ ), and firm. Percent kernel is $48.9 \%$ with a fat content of $63.8 \%$. It has a high level of resistance to low temperature (to $-25^{\circ} \mathrm{C}$ ).

'Pervomaysky'. The trees are medium size ( 6.5 $\mathrm{m})$, late leafing, and annual fruiting with a yield capacity of $32 \mathrm{~kg} /$ tree and an average nut weight of $10.6 \mathrm{~g}$. The shell is light straw colored, thin $(1.2 \mathrm{~mm})$, and firm. Percent kernel is $50.1 \%$ with a fat content of $58.7 \%$.

'Krymsky Urozhayny'. The trees are medium size $(5 \mathrm{~m})$ and annual fruiting with a yield capacity up to $37 \mathrm{~kg} /$ tree and an average nut weight of $12.2 \mathrm{~g}$. The shells are thin $(1.2 \mathrm{~mm})$, light yellow color, and firm. Percent kernel is $57.7 \%$ with a fat content of $63.7 \%$.

Walnut cultivars with high percentage protein kernels include 'Krymsky Yubileyny' (23.4\%), 'Bomba Chkalovskaya' (25.7\%), 'Bulganaksky 26' (24.5\%), 'Partizansky 281' (26.3\%), and 'Nikitsky 31' (23.7\%) (Rikhter and Yadrov, 1985).

Hazelnut. The hazelnut germplasm collection and breeding program was renewed in 1994 with the introduction of the best foreign cultivars. Continued studies, evaluations, and breeding are ongoing, using the best local hazelnut cultivars and selections found growing in the varied climatic zones of Crimea. The hazelnut collection at the NBG consists of 16 cultivars and 29 selections expressing desirable breeding characteristics. Improved hazelnut cultivars for Crimea are being developed by crossing superior, well-adapted local cultivars with the best foreign material. As a result of this work, there is a large amount of material currently being evaluated by Sergei Yu. Khokhlov.

Pomegranate. Nina K. Arendt began working on pomegranate at the NBG in 1946. The collection is currently one of the largest in the former Soviet Union with 370 accessions, and is the only one in Ukraine. This material was collected during expeditions to Central Asia and the Trans-Caucasus and was also introduced from Iran, Afghanistan, Spain, Italy, and the U.S. The main selection criteria are early ripening fruit, high yield, fruit mass of 300 to $350 \mathrm{~g}$, dark color, total sugar content of $14 \%$ to $15 \%$, and a juice yield of $60 \%$ to $65 \%$. Today, Tatyana V. Litvinova continues the pomegranate program at the Gardens.

Chinese date. In 1953, Lidiya T. Sinko organized collections of chinese date from China, Central Asia, Azerbaijan, Georgia, and Crimea. Presently, the collection holds 140 cultivars and forms with ongoing evaluation and breeding work done by T.V. Litvinova.

Fig. Nina K. Arendt developed the fig program at the NBG. She collected $>300$ cultivars and forms including native selections and cultivars introduced from Albania, Azerbaijan, Bulgaria, Georgia, Turkey, Tunisia, France, Israel, Italy, U.S., Germany, and Yugoslavia 
(Arendt and Rikhter, 1960). There are currently 30 cultivars in the collection at the NBG. Today, Alexander N. Kazas and Elena L. Shishkina continue the work with figs.

\section{Top fig cultivars of the NBG}

'Podarok Oktyabryu'. Light-green skin, dark pink flesh, and average fruit weight of 60 to $70 \mathrm{~g}$. Dried fruit type that requires cross-pollination.

'Nikitsky'. Dark-blue skin, carmine-red flesh, and average fruit weight of 40 to $50 \mathrm{~g}$. Canned fruit type that requires cross-pollination.

'Smena'. Yellow skin, pink flesh, and average fruit weight of 60 to $65 \mathrm{~g}$. Dried fruit type that requires cross-pollination. This cultivar resulted from interspecific hybridization between 'Kadota' and Broussonetia papyrifera L. pollen.

'Zheltoplodny Urozhainy'. Light-yellow skin, pink flesh, and average fruit weight of 60 to 65 g. Suitable for drying and canning, and requires cross-pollination. This cultivar resulted from mutation breeding work with 'Smena'.

'Sabrutsiya Rozovaya'. Brown-red skin, pink flesh, and average fruit weight of $90 \mathrm{~g}$. Table type that requires cross-pollination. This cultivar was selected from apomictic seedlings of 'Sara Lob'.

Persimmon. There are four species of persimmon held in the NBG collection: Diospyros kaki L., D. lotus L., D. virginiana L., and $D$. sinensis $\mathrm{L}$. The last three species have small fruit and are usually used as rootstocks for D. kaki (Arendt and Rikhter, 1960). The germplasm collection created by Nina K. Arendt and Arkadiy K. Pasenkov numbers 190 cultivars and unique forms of native and foreign origin, including 40 introduced from China and Japan. Two cultivars 'Rossiyanka' and 'Nikitskaya Bordovaya' developed at the Gardens have high frost tolerance. They have endured temperatures of $-24^{\circ} \mathrm{C}$ without damage. The fruit of 'Rossiyanka' and 'Nikitskaya Bordovaya' have masses of 100 and $130 \mathrm{~g}$, respectively. Both cultivars are of the astringent type. Today, Alexander N. Kazas continues the work with persimmon.

\section{Top persimmon cultivars of the NBG}

'Sputnik'. A productive, monoecious, nonastringent type with $100 \mathrm{~g}$ fruit that has been regionalized on the south Crimean coast. 'Mechta'. A high-yielding, monoecious, as- tringent type with red-orange fruit of up to $200 \mathrm{~g}$.

'Ukrainka'. An early-ripening, monoecious, non-astringent type with $100 \mathrm{~g}$ fruit. Coloring of fruit begins in early September.

Olive. The first olive trees were planted at the NBG in 1822. Nina K. Arendt began breeding and evaluation work in 1927. Violetta A. Sholokhova continued this program in 1960. Currently, there are 228 cultivars and selections in the collection, including 126 foreign cultivars and 102 cultivars developed at the NBG. The main breeding objectives are precocity, early ripening and maturing, high oil content, cold hardiness, and high productivity. Today, Lidiya F. Myazina continues the olive program at the Gardens.

\section{Top NBG olive cultivars}

'Krymskaya Prevoskhodnaya'. Early ripening, large size $(6.7 \mathrm{~g})$ fruit with soft, aromatic flesh. The yield capacity is $4 \mathrm{t} \cdot \mathrm{ha}^{-1}$, the oil yield is $18 \%$ to $21 \%$, and it has universal use.

'Nikitskaya Krupnoplodnaya'. Large size (5.0 g) fruit with firm, oily flesh. The yield capacity is up to $6 \mathrm{t} \cdot \mathrm{ha}^{-1}$, the oil yield is $31 \%$, and it has universal use.

'Nikitskaya'. Medium size (3.0 g) fruit with firm, oily flesh. The yield capacity is up to $6 \mathrm{t} \cdot \mathrm{ha}^{-1}$, the oil yield is $36 \%$, and it has universal use.

Feijoa. The collection of Feijoa sellowiana Berg., also known as pineapple guava, at the NBG contains 400 accessions. The most promising selections have high consistent yields, high winter-resistance, are early ripening, and have fruit masses of 20 to 35 g. E.L. Shishkina currently conducts the Feijoa research.

Pawpaw. The collection of pawpaw (Asimina triloba) contains 16 foreign cultivars and $>80$ seedlings. The collection was planted in 1997 and it is the only one in Ukraine. Currently, selection of the best forms from open pollinated seed progeny has been done, with eight promising seedlings beginning to produce fruit. Khokhlov works on the introduction, breeding, and evaluation of pawpaw.

Contact Valery N. Yezhov (director), Nikita Botanical Gardens, National Scientific Center, 98648, Yalta, Crimea, Ukraine; phone 0654-33-55-97 or 0654-33-55-30; fax 0654-33-53-86; email nbg@yalta.crimea.ua. Anatoly V. Smykov and Vladimir K. Smykov; phone 0654-33-55-16 or 0654-33-68-68; fax (see above); email flora@gnbs.crimea.ua. Sergei Yu. Khokhlov; phone 0654-33-55-16 or 0654-33-68-68; fax (see above); email khohlov@mail.ylt.crimea.com. Contact with other plant breeders or scientists refered to in the manuscript can be first initiated through the authors Valery N. Yezhov (director), Anatoly V. Smykov, Vladimir K. Smykov, or Sergei Yu. Khokhlov.

\section{Conclusions}

In addition to being a beautiful botanical garden and tourist attraction set on the stunning southern coast of the Crimean peninsula, the Nikita Botanical Gardens contain one of the oldest and most diverse collections of temperate and subtropical fruit and nuts in Europe. The vast germplasm repository collected and maintained by the NBG for nearly 200 years represents a valuable resource for fruit and nut breeders worldwide. Cultivars and collections developed by outstanding breeders such as Kostina, Ryabov, and others at the Gardens established the foundation for fruit culture and industry in many parts of the former Soviet Union. Their work and the work of current scientists at the Gardens represent a tremendous body of knowledge and plant genetic resources that have yet to be fully utilized by breeders in the western world. This paper highlights these assets. The NBG looks forward to collaboration, cooperation, and the sharing of plant germplasm with interested scientists around the world.

\section{Literature Cited}

Andriyenko, M.V. 1997. Pomology (in Russian). vol. 3. Urojai, Kiev.

Arendt, N.K. and A.A. Rikhter. 1960. Species, cultivars, and the best hybrids of subtropical and nut species at the Nikita Botanical Gardens (in Russian). NBG Proc. vol. XXXIV. NBG, Yalta.

Smykov, V.K. 1989. Apricot (in Russian). Agropromizdat, Moscow.

Smykov, V.K. and A.I. Lischuk. 1999. Intensive fruit species breeding. NBG Proc. vol. 118. NBG, Yalta.

Kostina, K.F. 1936. Apricots (in Russian). The N.I. Vavilov All-Union Inst. Plant Ind., Leningrad.

Rikhter, A.A. 1972. Almond (in Russian). NBG Proc. vol. LVII. NBG, Yalta.

Rikhter, A.A. 1975. Catalog of nut species at the Nikita Botanical Gardens (in Russian). NBG, Yalta.

Rikhter, A.A. 1981. Manual for biology study of persian walnuts (in Russian). NBG, Yalta.

Rikhter,A.A. and A.A.Yadrov. 1985. Persian walnuts (in Russian). Agropromizdat, Moscow. 